\title{
STUDY ON OPERATION AND PERFORMANCE OF BUS PRIORITY POLICIES CONSIDERING INTENDED PLATOONING OF BUS ARRIVALS *
}

\author{
by Pradeep Kumar SHRESTHA ${ }^{* *}$ Fumihiko NAKAMURA ${ }^{* * *}$ Toshiyuki OKAMURA ${ }^{* * * *}$
}

\section{Introduction}

The quality of bus service has been concerns for all policy makers, operators and users. Transportation experts are exploring different alternatives ranging from space priority such as exclusive bus lane to the application of advanced Intelligent Transport System (ITS) technologies such as bus signal priority (BSP), automated scheduling and dispatch systems etc ${ }^{1,2)}$ for improvement of bus service. The preferential treatment to buses has been increasingly considered in transportation system for improving bus movements and operational efficiency. Exclusive bus lane is one of the approaches that avoid traffic congestion and the conflict of buses with other traffic, there by increasing average speed and decreasing delay of buses. The installation of Bus Rapid Transit (BRT) exclusive lane can effectively bring benefits the operation efficiency of BRT and improve the passenger carrying capacity of the road up to $40 \%{ }^{3)}$.

However, bus delay still exists as buses have to stop at bus stop while picking up passengers and stop at traffic signals during red time affecting bus operational efficiency. In case of high demand bus routes, if bus has been delayed for small amount of time, there will be increased numbers of passenger at next stop. The number of passengers to be picked up at the next stop increases quickly from average passenger demand which causes further delays. In addition, when passenger demand is high, it takes longer time to board and alight passenger in the crowded bus than that of noncrowded buses. As a result, the bus continues falling further behind schedule. On the other hand, the following bus would have fewer passengers than average numbers of passenger to pick up and lower dwell times, allowing it to catch up with the preceding. Furthermore, when buses have to stop at traffic signal, there is a natural tendency of buses bunching up into platoon ${ }^{4}$.

Most researches recommended the bus platoon is an undesirable because it tends to increase the variation in scheduled headways, demand and increase waiting times for passenger. Also, when two bus comes together, passenger might be in confusion that where and which bus will stop. It will some time create crowding and increase boarding time. Therefore, the most of researcher recommended that the potential control strategies should be focused on reducing bus platoon problem. Though the natural tendency of the bus platoon is undesirable, the intended bus operation in platoon has potential of maximizing the capacity of the bus system, reduce dwell time at stop, and less harm to other traffic when priority is to be given to buses. Operating two ore more buses in platoon could increase capacity of the system, there by reducing peak hour overcrowding of passengers in the buses. One of the analyses in TCRP- RRD- $38^{5)}$ suggested that one of the reasons for the Bogotá bus way is being able to move high passenger flows is due to the buses moving in platoons along the bus way. Each platoon consists of 12 to 16 buses with average 96 sec headways. Buses on the high demand routes are often articulated to increase the passenger carrying capacity. These buses not only require more than one loading area, they also have higher dwell times because of large crowd formation at their busiest boarding door ${ }^{6)}$. In such situation also, bus operation in platoon will be helpful to accommodate high demand.

Thus, this paper has attempted to design and test a strategy of systematic operation of buses in platoon along with other priority policies such as bus signal priority and exclusive bus lane. The bus operation in platoon with bus priority lane can maximize capacity and reduce cost of operation. The bus signal priority, given to bus platoon, will have less impact to other non priority vehicles as numbers of priority activation are decreased. However, when bus comes at bus stop together, the boarding of passenger should be regulated and directed into proper channel to avoid confusion among passengers. The bus operation in platoon has been considered on the exclusive curb bus lane having set back distance at the intersection approach for this study purpose. Additionally, the signal priority has been design to account the bus platoon. Three buses in platoon were considered and the results are compared with the normal bus operation. The result it was observed that the capacity of the bus lane was increased with reduction in delay. Later part, this paper discuss about implementation issues of bus platoon, challenges and solution measures to managed and control the system properly so that it would not give negative impact.

\footnotetext{
* Keywords: Bus Priority, Bus lane, Bus Platooning, Simulation

** Student Member of JSCE, M.Eng, Graduate School of Engineering, Yokohama National University (79-5 Tokiwadai, Hodogaya-ku, Yokohama, 240-8501 Japan, Fax: +81-45-339-4031, email: d06sc194@ynu.ac.jp)

*** Member of JSCE, Prof. Dr. Eng., Graduate School of Engineering, Yokohama National University (79-5 Tokiwadai, Hodogaya-ku, Yokohama, 240-8501 Japan, Fax: +81-45-339-4032, email: f-naka@ynu.ac.jp)

**** Member of JSCE, Dr. Eng., Graduate School of Engineering, Yokohama National University (79-5 Tokiwadai, Hodogaya-ku, Yokohama, 240-8501 Japan, Fax: +81-45-339-4033, email: tokamura@ynu.ac.jp)
} 


\section{Research Concept}

Reducing the bus conflict with other traffic, avoiding stop at traffic signal to ensure uninterrupted movement of bus, and way to increase capacity of the bus are three fundamentals for attractive bus system. The priority treatment of bus by providing exclusive bus lane has been widely considered to make bus free from conflict with other traffic. Thus, buses running in the exclusive bus lane are expected to be highly reliable on schedule, relatively easier to control. Also, the inclusion of other bus priority method such as bus signal priority while operating buses on exclusive lane can further guarantee the smooth flow of buses on the road. In addition to above mentioned bus priority policies, the developing platoon bus operation strategies can increase bus system capacity and efficiency. Of course, buses being in platoon on normally scheduled bus route will impose negative impact as it reduces the efficiency of the bus route network. It is worthy to note that well planned operation of bus platoon and their potential benefit has been focused by very little researchers. The platoon of buses moving in exclusive bus lane resembles that of commuter train with increased capacity than normal bus operation. The concept can be very effective during peak hour along the bus routes having heavy flow of passengers. The possible hindrances are control of bus movements to maintain platoon, safety concerns, estimating passenger demand beforehand, understanding and managing the passenger behavior at bus stop etc. Advancement of Intelligent Transportation System (ITS) have provided with varieties of tools to monitor, control and prediction methods. Thus, this study aimed to find the most effecting way of considering bus priority policies with intentional formation of bus platoon utilizing the benefits of ITS technologies. The main objectives of this study are:

1. To develop and test a strategy to operate bus on platoon

2. To study on the impact of considering bus platoon on the capacity of the bus priority lane policy, and

3. To discuss implementation issues, challenges and propose possible solution measures.

\section{Literature Review}

For bus routes with frequent service (headways less than 10 minutes), most passengers tend to pay less attention to printed timetables and generally arrive at bus stops at random, expecting small waiting times there. Therefore, for bus routes with service headways less than 10 minutes, the ability for buses to maintain a constant headway is important. Otherwise, service reliability is likely to deteriorate quickly, and bus bunching (i.e., a bus catching up to a bus in front) is likely to occur. Chavala,T. et $\mathrm{al}^{7}$ ) studied the compromised operation of one station has effects on the downstream stations as illustrated in Figure 1. Suppose a bus arrives 'on time' at station A and experiences peak hour passenger crowding at the station. The increased passenger crowd decreases the space available per passenger for walking, reducing their walking speed. In such cases the bus driver has to wait until all passengers reach the bus door and board. The bus needs to spend more time at the station and hence increases its dwell time and reduces the time gap allotted between the two bus arrivals causing a decrease in their headway. Further, when this bus reaches the next station (station B) and experiences the similar situation, the headway between the two bus arrivals reduces further. At some point in time this headway will be very small forcing buses to run one behind other forming 'bus bunching'. This situation is not attractive from the point of view of passenger as it may create uncertainty (Figure 1).

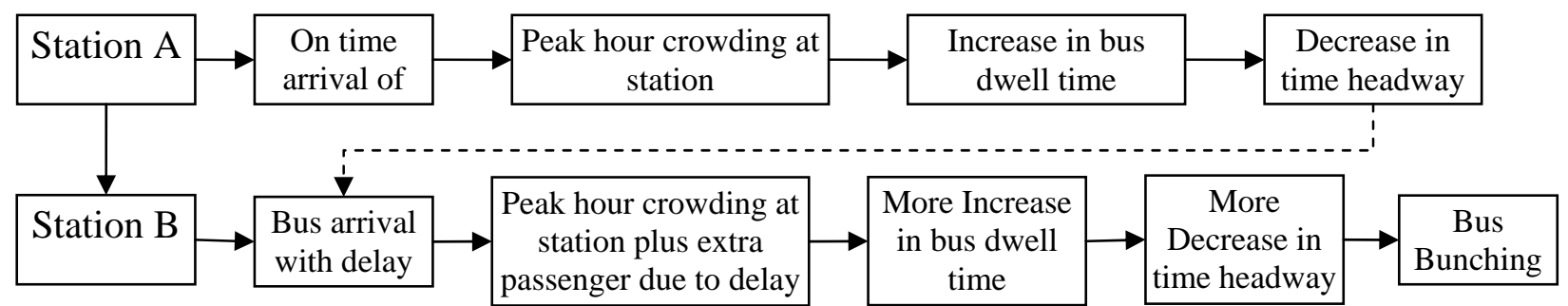

Figure 1 Peak hour crowding at station plus extra passenger due to delay

One of the factors that affect the bus capacity of an arterial street bus lane is whether or not buses move along the lane in platoons. Jacques and Levinson ${ }^{5}$ explained that if three buses could be processed each cycle, the capacity of the bus lane would be 195buses/hr, and average bus speeds would be approximately $13 \mathrm{mph}$ (including dwell times). Also, the platoon of buses appears to create a higher efficiency in the bus berth use.

In Porto Alegre, Brazil, high-capacity bus convoy system was developed, and it evolved into Bus Ordering system in which buses are allocated to one of three groups (A-B-C) as shown in Figure 2. The buses arrive and are marshaled

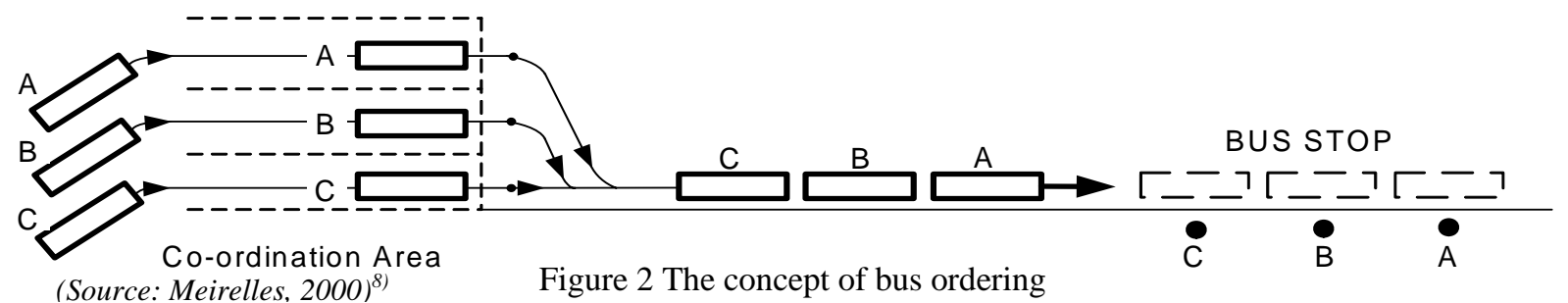


into the preferred sequence, though not into strict convoys. This system operates effectively and can improve commercial speeds at high levels of passenger demand (more than 30,000 passengers per hour per direction). This type of bus operation system could enhance the capacity of bus transit system with exclusive bus way up to that of rail based line haul transit system. ${ }^{8)}$

\section{Research Methodology : The Micro-simulation Approach}

The intended bus platoon operation is aimed to increase capacity of bus lane in the high demand bus route and its effects. The following sections explain about the assumptions made, scenario considered, data collection and evaluations etc.

\section{(1) Organizing bus platoon}

The developing platoon bus operation strategies can increase bus system capacity and efficiency. The platoon of buses moving in exclusive bus lane resembles that of commuter train with increased capacity than normal bus operation. The individual driver in the bus will control and maintain the headway of buses. The concept can be very effective during peak hour along the bus routes having heavy flow of passengers. A bus platoon of three buses was considered in this study and moved with average speed of $35 \mathrm{KPh}$. The bus stop is to be marked with the proper position and bus will stop at assigned position for passenger convenience and ease in boarding and alighting. It is assumed that the rear buses in the platoon will move according to the speed of lead bus maintaining safe distance.

(2) Considering bus priority policies

Bus priority methods are a range of techniques designed to speed up buses and improve overall system efficiency. The bus lane and signal priority are two of techniques of bus priority considered for this study. The purpose of both priority policies is to maintain uninterrupted smooth flow of buses.

a) Bus exclusive lane

The exclusive bus lane (Figure 3 (a) \& (b)), by definition, means a lane which is permitted to use only by buses and other vehicles are prohibited to use it. Both continuous bus lane (Figure 3 (a)) which penetrates through intersection or set back type (Figure 3 (b)) which terminate at certain distance before intersection approach and/or begin at certain distance ahead of intersection, have been considered along with other priority method such as signal priority. The exiting situation in the field consists of two general purpose lanes in main road and one lane in cross road.

Set back bus lane maintains the capacity of intersection approach provided that the length of set-back is well enough. Set back bus lane is allowed to use exclusively by buses only beyond set-backs and all vehicles arrived at intersection during red time can queue at the set back length till it has been filled. It is to be noted that long set back distance will harm bus benefit without significant benefit to other vehicle. Jepson and Ferreira ${ }^{9)}$ have recommended set back distance of 1.3 meter per sec green time of approach i.e. 40m set back distance for the observed 33 sec green time at the selected intersection. Additionally, the effect of range of set back distances were assessed through separate traffic simulation modeling in CORSIM ${ }^{10,11)}$ simulation package for exclusive purpose of selecting suitable cases among the cases mentioned in Table 1 below. Since, the main objective of this part is just to select the suitable option for further analysis, the details of simulation has not been included here. The measures of effectiveness such as bus and vehicle delay, vehicle discharge etc were compared as in Table 1. From Table 1, bus delay and vehicle discharge increases where as vehicle delay decreases with increase in set back distances. The vehicle discharged for the set back distances of $80 \mathrm{~m}$ and $100 \mathrm{~m}$ is not statistically different with base case. Also, the average queue observed in the field at the end of red time for lane 1 was about $82.5 \mathrm{~m}$. Thus, $80 \mathrm{~m}$ set back length was selected for setback bus lane.

Table 1 Comparison of Delay and Vehicle discharged

\begin{tabular}{|l|c|c|c|}
\hline \multicolumn{1}{|c|}{ Options } & $\begin{array}{c}\text { Bus Delay } \\
\text { (Sec/bus) }\end{array}$ & $\begin{array}{c}\text { Vehicle Delay } \\
\text { (Sec/Veh) }\end{array}$ & $\begin{array}{c}\text { Vehicle discharged } \\
\text { (Veh/hr) }\end{array}$ \\
\hline Base: 2 General Lane & 90.29 & 36.67 & 897 \\
\hline Option 1: 1 General lane and 40m set back bus lane & 74.72 & 70.62 & 800 \\
\hline Option 2: 1 General lane and 80m set back bus lane & 75.79 & 63.23 & 883 \\
\hline Option 3: 1 General lane and 100m set back bus lane & 77.69 & 53.33 & 888 \\
\hline Option 4: 1 General lane and 1 continuous bus lane & 69.02 & 85.24 & 649 \\
\hline Option 5: 2 General lane and extra continuous bus lane & 68.67 & 47.02 & 925 \\
\hline
\end{tabular}

Similarly, bus lane continued through the intersection provided by converting existing lane may affect capacity of the road severely. Thus, option 4 and option 5 was considered to decide suitable continuous type bus exclusive lane as shown in Table 1. Converting one lane into continuous exclusive bus lane has increased delay to general vehicles up to $85.24 \%$ and decreased in vehicle discharge to $649 \mathrm{veh} / \mathrm{hr}$. Thus, extra lane was considered as continuous exclusive lane along with existing two general purpose lanes for this study. 


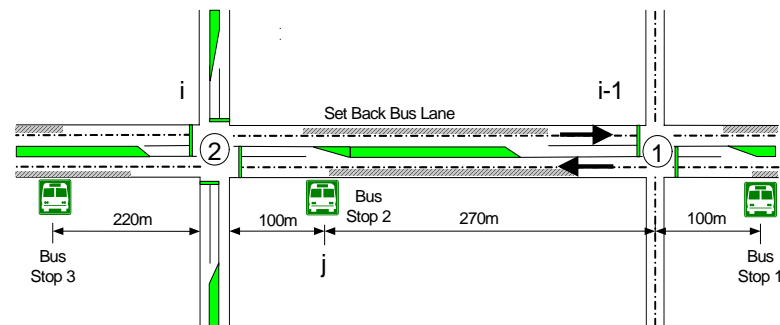

Figure 3 (a) Schematic layouts (Set back bus lane)

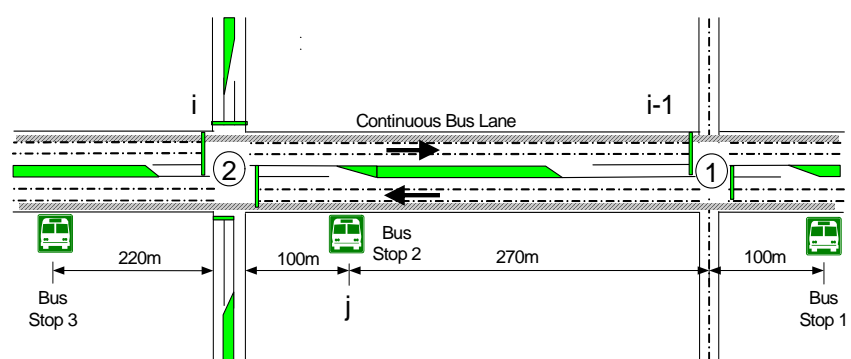

Figure 3 (b) Schematic layouts (Continuous bus lane)

b) Bus Platoon Based Priority Signal Timing

Signal priority logic was developed to change traffic signal parameter in order to give priority to bus platoon. The priority logic includes bus detection at user specified distance, prediction of time at which bus will arrive at intersection stop line or join intersection queue, decide bus priority scheme according to bus arrival time and granting priority.

(i) Bus Platoon Arrival Time: The total time for a last bus in the bus platoon to travel from the detector to the intersection stop line in bus lane was computed as the sum of average bus travel time of first bus in the platoon to reach stop line and the time to reach remaining all other buses in the platoon, as shown in Equation (1) below:

$T_{1}=\frac{3.6 \times L_{1}}{v_{1}}+(n-1) \times h_{p}$

Where, $\mathrm{T}_{1}=$ Travel time of last bus in bus platoon to reach the stop line for approach (1) as shown in Figure 4 (sec); $\mathrm{L}_{1}=$ Length of road from the detector to stop line (m); $\quad v_{1}=$ Approach speed on the major road $(\mathrm{km} / \mathrm{hr})$; $\mathrm{n}=$ Numbers of buses in platoon; $\mathrm{h}_{\mathrm{p}}=$ average bus headway in the bus platoon (seconds); since ' $L$ ' and ' $v$ ' is in meter and $\mathrm{km} / \mathrm{hr}$ respectively, the coefficient 3.6 was included to convert speed into $\mathrm{m} / \mathrm{sec}$.

(ii) Minimum Green Time for Side Street: The minimum green time depends on the time required for pedestrian to cross the street or Local rules. The Highway Capacity Manual (HCM) ${ }^{12)}$ of United States has recommended the empirical relation as shown in Equation $(2)^{12)}$.

$$
G_{\text {min }}=3.2+\frac{L}{v_{p}}+\left(0.81 \frac{N_{p}}{W_{E}}\right)
$$

Where, $G_{\text {min }}=$ minimum green time (s), $L=$ crosswalk length $(m), S_{p}=$ average speed of pedestrians $(m / s), W_{E}=$ effective crosswalk width (m), 3.2 = pedestrian start-up time (s), and $\mathrm{N}_{\mathrm{p}}=$ number of pedestrians crossing during an interval (p).

(iii) Bus Priority Scheme: The priority schemes rely on detection of the platoon arrival, minimum green time, maximum green time etc and most of all existing signal plan. Figure 5 (a) illustrates a signal phase plan including phase sequence, their respective values in seconds and force off points for the intersection 2. It consists of four phases such as main road through and left turn phase, main road right turn phase, cross road through and left turn phase, and cross road right turn phases, and are denoted as $\Phi_{1}, \Phi_{2}, \Phi_{3}$, and $\Phi_{4}$ whose force off points are $T_{1}, T_{2}, T_{3}$, and $T_{4}$, respectively as shown in Figure 5 (a). The force-off points are the points at which current phase terminates and clearance interval begins. The phase ' $\Phi_{1}$ ' is the priority phase and coordinated for through movements on the main road. Signal is set at a certain offset to achieve the signal coordination of green interval. The coordinated phases must always be green at a fixed time and continued green until its force-off point. During signal priority, coordination phase is maintained by keeping green until a fixed point in cycle and forcing off other non coordinated phases. The total cycle time and off set remained same and non-priority phases will be reduced to give priority.

Green extension and early green are two major priority logics considered for this study. The green extension is used when the upper level of priority can be accommodated by extending green as shown in Figure 5(b). The force-off point, $\mathrm{T}_{1}{ }^{\text {ext }}$, of the green extension strategy is set at the upper value i.e. end of maximum green extension time as shown in Figure 5(b). The maximum green time extension, ' $G_{\max }$ ', is the difference between cycle time, and sum of green time $\left(G_{i}\right)$ of main

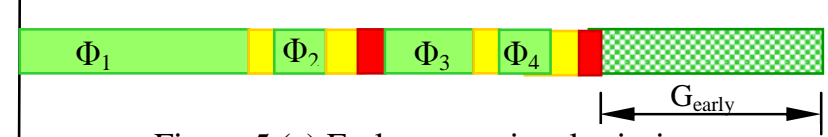

Figure 5 (c) Early green signal priority

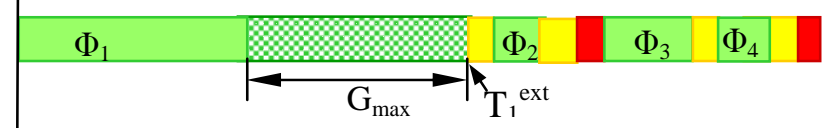

Figure 5 (b) Green extension signal priority

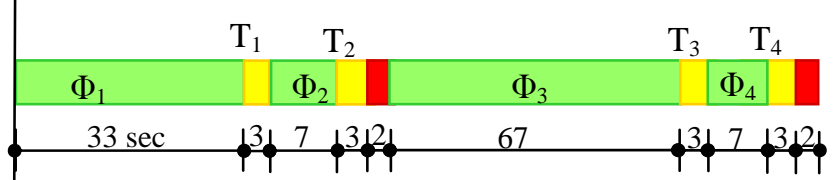

Figure 5 (a) Existing signal phases for Intersection 2

0

Time, $\mathrm{T}$ 


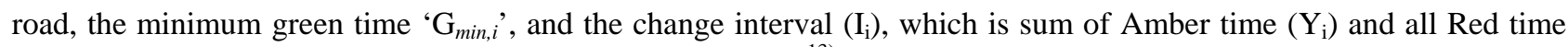
$\left(A_{i}\right)$, of all non-priority phases, can be shown in Equation (3) ${ }^{13)}$.

$$
G_{\max }=C-G_{1}-\left\{\sum_{i=2}^{n} G_{\min , i}+\sum_{i=1}^{n}\left(Y_{i}+A_{i}\right)\right\}
$$

Where, i, C, G, Y, A and I are phase, cycle time, green, amber, all red time and change interval. For the phase diagram shown in Figure 5 (a), the phase 2 and phase 4 is very short as the observed traffic flow for this movements are small. The green time for phase 2 and 4 are themselves considered as minimum green time and minimum green time for phase 3 is $30 \mathrm{sec}$. Then, the maximum green time according to Equation (3) will be $G_{\max }=$ (130-33$[\{7+30+7\}+\{3+(3+2)+3+(3+2)\}]=37$. The upper and lower values of green extension can be calculated as per Table 2 which is 33 and $70 \mathrm{sec}$, respectively.

Similarly, if a bus is expected to arrive during the red signal and upper level of priority cannot be accommodated by green extension, then the non-priority phases is shortened to allow the main street to receive a green earlier than normal as shown in Figure 5 (c). The early green depends on the number of non-priority phases between the current phase at which bus arrives and the main street phase. The current phase is stopped or provided the minimum green, and its change interval initiated. The maximum early green time is the difference between the cycle time, and phases that has already been served, the maximum of elapsed green of the current phase $\left(t_{k}\right)$ and its minimum green $\left(G_{\min , k}\right)$, and minimum requirements of phases $\left(G_{\min }, I_{i}\right)$ as shown in Equation $(4)^{13)}$. Where, ' $\mathrm{i}$ ' and ' $\mathrm{k}$ ' are numbers of phases and the phase during which bus will arrive, respectively.

$$
G_{\text {early }}=C-\left\{\left(G_{1}+I_{1}\right)+\sum_{i=2}^{k-1}\left(G_{i}+I_{i}\right)+\left\{\max \left(G_{\min , k}, t_{k}\right)+I_{k}\right\}+\sum_{i=k+1}^{n}\left(G_{\min , i}+I_{i}\right)\right\}
$$

Lets suppose, Bus is to arrive at phase ' $\Phi_{3}$ '. From the field observation, the phase 2 and 4 are very small and can be considered as minimum green. Then, the early green can be computed as Equation (5),

$$
G_{\text {early }}=C-\left\{\left(G_{1}+I_{1}\right)+\left(G_{2}+I_{2}\right)+\left\{\max \left(G_{\min , 3}, t_{3}\right)+I_{3}\right\}+\left(G_{4}+I_{4}\right)\right\}
$$

For example; bus arrived in phase 3 at the elapsed green time of $40 \mathrm{sec}$, then, early green can be calculated for phase diagram Figure 5 (a) using Equation (5) as $\mathrm{G}_{\text {early }}=(130-\{(33+3)+(7+5)+\{\max (30,40)+3\}+(7$ $+5)\})=27$. The upper and lower values of early green are 130 and 103 sec as per Table 2.

Table 2 Upper and lower values of signal priorities

\begin{tabular}{|l|c|c|c|c|}
\hline & \multicolumn{2}{|c|}{ Upper value } & \multicolumn{2}{c|}{ Lower value } \\
\hline Green extension & $\mathrm{T}_{1}+\mathrm{G}_{\max }$ & $(33+37)=70$ & $\mathrm{~T}_{1}$ & 33 \\
\hline Early Green & $\mathrm{C}$ & 130 & $\mathrm{C}-\mathrm{G}_{\text {early }}$ & $130-27=103$ \\
\hline
\end{tabular}

(3) Scenarios

The considered bus operation includes the light rail look-alike three buses forming bus platoon which moves through the bus exclusive bus lane along with consideration of bus signal priority based on bus platoon whenever necessary. Exclusive bus lane considered were continuous bus lane which penetrates through intersection or set back bus lane with setback distance of $80 \mathrm{~m}$ (refer section $4(2)$ (a)) before intersection approach. Thus, the following three cases were tested and comparative analyses were carried to draw out suitable bus operation recommendation considering bus platoon and bus priority policies.

- Case A : Normal bus operation with BSP

- Case B : Bus platoon operation in setback bus lane with BSP

- Case C : Bus Platoon operation in continuous bus lane with BSP

Also, the benefit of the concept of bus operation in platoon was assessed considering two application cases mentioned below:

Case I (Increased Efficiency case): The system efficiency impact to other traffic and use of resources could be reduced incase buses are running in larger headway. The travel time of other traffic will be least harmed in the cases such as bus signal priority. Also, the bus operating in platoon can be one of the alternatives to maintain the capacity of the bus route to be operated under larger headway. For example from passenger perspective, there will not be much difference whether buses come every 2 minutes or 6 minutes provided that time schedule \& supply has been maintained. The single bus operating at 2 min headway can be increased to 6 minutes headway by operating three buses in platoon.

Case II (Increased Capacity case): In case of high passenger demand corridor, supply should also be higher either by running bus at small head way or using high capacity buses to accommodate all demand. However, it is not desirable to run buses at very small headway. In such case of large volume of waiting passenger at bus stop, the crowding takes place and dwell time may be exceptionally large while processing all passengers in single bus. Buses operating in platoon can provide additional supply at same headway. Assumption is that total passengers will be shared between total numbers of buses in platoon.

(4) Case Study Area

The real world case study is to be carried out to see the effect of the range of the alternative situation considered. The basic data collection had been carried out at the Fujisawa City of Japan, situated $50 \mathrm{~km}$ west of Tokyo. The corridor consists of the bus route carrying commuters to the Tsujido railway station which passes through the major intersection with National Highway 1 that brings travelers to Yokohama downtown. Field surveys were conducted during 7.00- 
10.00 of weekdays during peak hour time and randomly selected 3 weekdays of May 2008.Physical characteristics of the site such as road geometry, intersection layout, lane configuration etc. considered for this study has already shown in Figure 3 (a) and (b). Series of 2 intersections and road configuration with near side stop were considered and alternative cases were examined. The 15 min traffic volume in main and cross road Traffic signal parameters (cycle time, offsets, phase length etc) for entire data collection period was obtained through video recording and further processing at laboratory. Arrival and departure of the buses were recorded using video cameras, which were positioned at the bus stop and the convenient places of intersection. The bus related data includes average bus speed, headway, bus dwell time, time of joining traffic queue, and passenger related data such as on and off passengers counting.

The bus demand on the main road was higher due to the travelers commuting from and to Tsujido railway station and very few buses were observed in cross road. Hence, The bus route was only considered in main road with bus stop located at average distance of $100 \mathrm{~m}$. The basic data used for modeling are road geometry data, turning movements (Figure 6), queue discharge headway $=2.4 \mathrm{sec}$, mean dwell time $=15$ sec with bus headway $=240$ sec. Total cycle time of main road is $130 \mathrm{sec}$. The green times are $90 \mathrm{sec}$ and 33 second for Intersection 1 and 2 respectively with minimum green time of 30sec. The traffic signal operates in a coordinated mode for through traffic in main road. During signal priority, coordination phase was maintained by keeping green until a fixed point within cycle and changing other non phases, which was explained in section 4 (2) (a) too.

(5) Simulation Evaluation

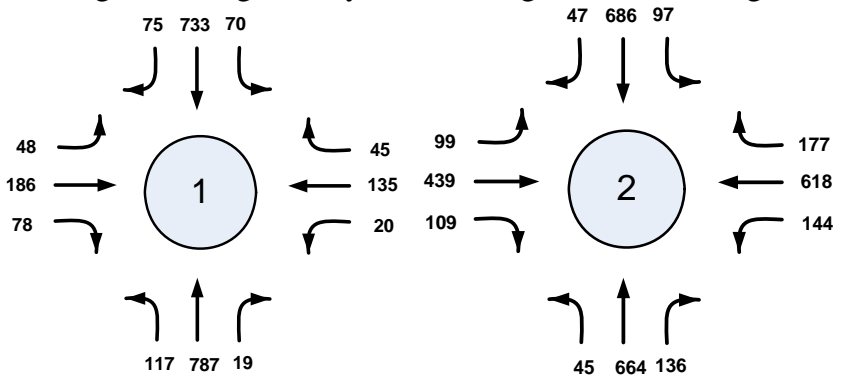

Figure 6 Turning movements at intersection 1 and 2

CORSIM $^{10,11)}$ Simulation was adopted for modeling the scenario cases and evaluate the road operations impacts of bus priority lane along with platoon arrival of buses. CORSIM is a microscopic traffic simulation program that combines two separate programs one for modeling arterial streets, called NETSIM, and other one for modeling freeways, called FRESIM. CORSIM simulation runs were performed for the road network shown in Figure 3 (a) and (b) and traffic data mentioned in section 4 (4). The following sub sections have briefly explained about various issues of simulation in relation to this research:

(a) Vehicle operation

CORSIM ${ }^{10,11)}$ models individual vehicle movements based on car following and lane changing theories on a second by second basis. Vehicles enter into network randomly through entry link based on normally distributed vehicle entry headways. Vehicle characteristics such as vehicle type, driver type, desired lane, speed are assigned stochastically. Vehicle operation maintains the lane change behavior, gap acceptance etc which depend on randomly selected driver type. Simulation assumes that the follower vehicle will maintain a desired gap with leader and also, leader will follow network characteristics. A follower vehicle may make lane change upon finding desired gap if leader is traveling at slower speed and also vehicle make compulsory a lane change due to a lane drop, exit, turn, or blockage etc.

(b) Bus operation

Bus operation was simulated in CORSIM by defining bus route, bus headway, bus stop and bus dwell time distribution. At first bus routes were defined by assigning path node through which bus travels and bus stops where bus dwells. Buses are produced in CORSIM at a fixed interval per route inputted. Bus route offset was used to offset the time at which a bus route generates first bus. Then, other buses will be generated according to headway specified. Bus stops are identified by station numbers. It is defined by the distance of its downstream end from the downstream stop line, and by its capacity for holding buses. The bus stop dwell time distribution was assigned to determine the average time a bus spends at a bus stop. The bus can be assigned to exclusive bus lane, by defining lane as a bus only lane in lane channelization option. The interaction of bus with other vehicles also follow car following, lane change and gap acceptance criteria depending on randomly assigned driver type. In mixed traffic, when bus stops at stop, the follower vehicles will wait behind the bus or switch lanes if there are gaps in the adjacent lane. If bus station is at capacity, bus will wait for an available space before entering the station.

(c) Formation of Platoon:

Platoon size of bus platoon depends on the demand of the bus route. Since, the observed bus demand along the route selected for data collection period was observed to be 0.683 buses per minute with average dwell time 15 sec, the average platoon size selected for this study was 3 buses per 4 minute headway. AASTHO (2000) ${ }^{14)}$ recommended minimum safe stopping distance for speed of $35 \mathrm{kmph}$ as $46 \mathrm{~m}$. Thus, the selection of $5 \mathrm{sec}$ headway between buses in the bus platoon for $35 \mathrm{~km} / \mathrm{hr}$ free flow speeds would be safe. Also, it is to be noted the headway can be reduced, if the automated bus control was assumed through ITS technologies. The particular tool for bus platoon is not available in CORSIM simulation package. However, platoon arrival of buses was made possible by using bus route, bus stop and bus route offset properties. To generate three buses in platoon, 3 routes were inputted in the bus route properties with offset of each route equivalent to the assumed headways. The buses will generate and move into the network in platoon with headway of 5 sec between them. The variation in headway may only result due to variation in bus dwell time variation and traffic signal. The capacity of bus station was adopted as three so that the all buses in platoon could be served at the same time. 
(d) Left turn behavior

Curb side bus lane complicate traffic movements at the intersection approaches as the left-turn movements parallel to the bus lanes need to turn from the right-hand side of a bus lane. Thus, the lane alignment tab of intersection properties dialogue box was used. The lane right to the bus lane is aligned with lane in cross road to guide left turn properly. Similarly, turning movements from cross road lanes are also properly aligned with lanes other than bus lane so that vehicle will turn into general purpose lane. After carrying out simulation, graphic user interface was used to observe vehicle turning movement behaviors. Though lane alignments were made, the left turning vehicles especially from lane adjacent to bus lane found to violate the bus lane and turn to the left through bus lane. However, vehicle just found to use bus lane during turning, and vehicles were not found to block the bus lane or interfere the bus movement. In real world also, bus lane violation could not be stopped completely.

(e) Calibration of Simulation Model:

Before proceeding with simulation, the CORSIM should be calibrated and validate for its measures of performances (MOEs) so that they can match those in the field. The CORSIM was calibrated for capacity, traffic volume and travel time to represented field conditions. The parameter considered for alterations were mean discharge headway, mean startup delay, reaction time and mean free flow speed etc. The calibration process is the iterative process as altering a parameter could cause one factor to calibration target where as other factor move away from target value. The iterations were repeated until the calibration MOEs were within $15 \%$ of field value ${ }^{10,11)}$.

(f) Signal priority implementation

The CORSIM Run Time Extension (RTE) ${ }^{10,11)}$ capability was used to model and simulate the signal priority logic considered. Signal priority logic was developed to change traffic signal parameter in order to give priority to buses. The priority logic includes bus detection at user specified distance, prediction of time at which bus will arrive at intersection stop line, decide bus priority scheme according to bus arrival time and granting priority (Figure 7). The priority logic can be explained as follows:

1. The detector placed at the end of bus stop detects bus

2. If bus was detected, the information will convey to control centre.

3. The arrival of last bus of bus platoon was predicted at intersection by Equation (1), explained in section 4(2) (a).

4. The control system will determine signal priority strategy according to the priority schemes explained in section 4(2) (a).

(g) Simulation Runs

Then, simulation is carried out to find measures of effectiveness (MOE) with regard to various cases of BSP systems such as delay, average travel time, speeds of bus and other vehicles along priority and cross road. Because

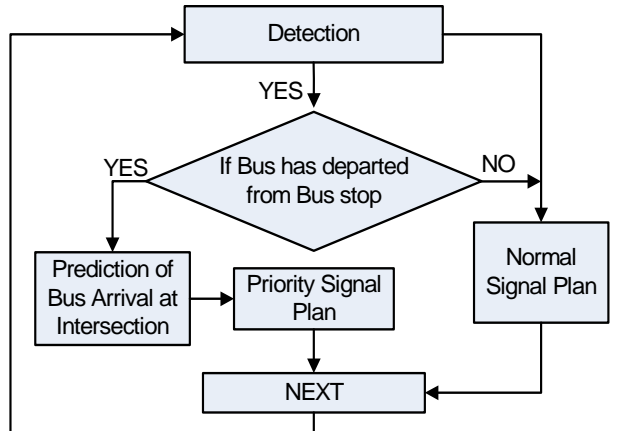

Figure 7 Flow diagram of BSP Activation of the stochastic nature of simulation, each simulation produces significantly different results. Thus, six different simulations run were performed with different random number seeds for the period of an hour between 7:30 to 8:30 and results were averaged to get more reliable result. Most simulation studies have used between five to ten repetitions with different random seeds ${ }^{15}$.

\section{Analysis and Results}

This study compared average speed, average travel time and delay for bus, traffic priority direction and traffic on nonpriority direction for the combination of Platoon bus operation in bus lane with bus signal priorities.The important measures of performances such as traffic flow (veh/hr), bus and other vehicle delay (sec), travel time (sec) and average speed (kmph) etc on main , cross road, and bus were obtained separately from CORSIM simulaion analysis.

(1) Effect on the traffic and bus flow of the system

The aim of providing set back bus lane is to maintain the capacity of the intersection approach. Thus, the bus flow and traffic flow through the intersection approaches were compared as shown in Figure 8. Figure 8 shows percentage change in the traffic flow for three cases mentioned at section 4 (3) with respect to base case without any kind of priorities. Case A (normal bus operation with BSP) has resulted increase in bus flow and vehicle flow in priority direction. As three bus platoon has been considered, the bus flow was about three times compared with normal bus operation with BSP. Set back bus lane with $80 \mathrm{~m}$ set back distance has shown $1.3 \%$ decreased in traffic flow. The t-statistics shows that the difference of traffic flow between base case and set back bus lane with BSP is not significant at $5 \%$ level of significance. It means set back distance does not reduce the traffic capacity of approach significantly.

Extra lane was considered as continuous bus lane since the converting exiting lane into continuous bus lane has affected general vehicle severely (Also explained in section 4 (2) (a)). The bus platoon operation on continuous exclusive lane with bus signal priority shows increase in traffic flow where as the bus flow and traffic flow on cross street for both case B and case C is similar. It can be concluded that the bus platoon operation with provision of extra continuous lane has increased performance. But the addition of extra lane cost a lot and may not be suitable option. In such case, Case B (bus platoon in set back bus lane) can be suitable option as it was found to affect little on exiting traffic flow. 
(2)Effect on Bus Measures of Effectiveness

This part explains about the effect of bus priority policies considering the intended operation of bus in platoon on bus measures of effectiveness. Three cases, namely (i) normal bus operation with Bus signal priority, (ii) the three bus platoon operation set back bus lane with BSP, and (iii) three bus platoon operation continuous bus lane, have been compared with original base case as shown in Table 3 below. Since extra lane has been considered for continuous bus lane, bus has got higher benefit of delay reduction and increased speed has been observed for case $C$. While testing hypothesis test for each case with respect to the original base case to see whether observed MoEs are different than that of Base case, the MoE for speed are insignificant for the case of normal bus operation with BSP and bus platoon operation in setback bus lane.

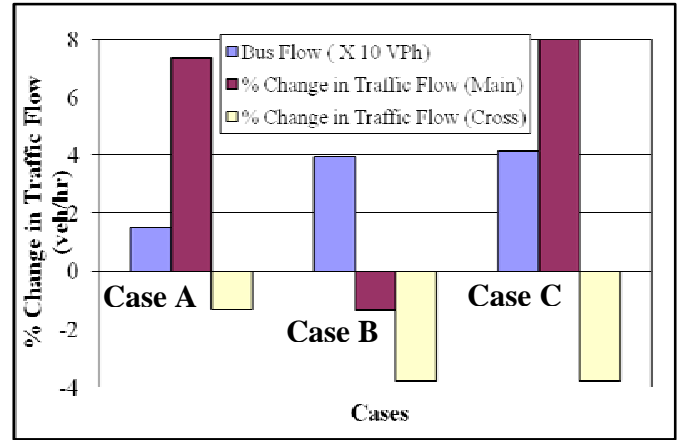

Figure 8 Effect on the capacity of the system Though it has not been shown in table, the total numbers of buses served for normal case are about 14 where as 40 buses for bus platoon.

Table 3 Measures of Effectiveness for Bus Operating under different cases

\begin{tabular}{|c|c|c|c|c|c|c|c|c|}
\hline & \multicolumn{2}{|c|}{ Base Case } & \multicolumn{2}{|c|}{ Case $\mathrm{A}$} & \multicolumn{2}{|c|}{ Case B } & \multicolumn{2}{|c|}{ Case C } \\
\hline & Delay & Speed & Delay & Speed & Delay & Speed & Delay & Speed \\
\hline Mean & 1.049 & 19.664 & 0.806 & 21.901 & 0.795 & 21.205 & 0.645 & 23.912 \\
\hline St. Deviation & 0.294 & 12.024 & 0.252 & 10.002 & 0.153 & 8.441 & 0.118 & 6.534 \\
\hline Count & 87 & 87 & 83 & 83 & 87 & 87 & 88 & 88 \\
\hline \multicolumn{3}{|c|}{$t_{\mathrm{cal}}$} & 5.806 & -1.434 & 7.159 & -0.866 & 11.915 & -2.899 \\
\hline \multicolumn{3}{|c|}{$\mathrm{t}_{\text {crit }}$} & 1.67 & 1.67 & 1.67 & 1.67 & 1.67 & 1.67 \\
\hline \multicolumn{3}{|c|}{ Remark } & Signf & Not Signf. & Signf & Not Signf. & Signf & Signf \\
\hline
\end{tabular}

(3)Effect on Other Vehicles Measures of Effectiveness

Three measures of effectiveness s has been collected from the simulation and compared among the four scenarios as shown in Figures 9 and 10. Delay, queue time for Main Street has found to decrease in bus platoon operation on exclusive lane with BSP. Similarly, Total stop time on cross street has decrease for the Bus platoon operation with BSP and Exclusive lane. Measures of effectiveness for Case A (Normal bus operation with BSP) and Case B (Platoon bus operation with Set back bus lane) are similar. Thus, Bus operation in platoon can be employed to increase passenger carrying capacity of the bus route with important bus priority measures maintaining impact to other vehicles.

(4) Case I (Increased Efficiency case)

The case I assumed that the system efficiency, impact to other traffic and use of resources could be reduced. Under the assumption that there will not be much difference for passenger whether buses come every 4 minutes or 12 minutes during low demand situation, provided that time schedule \& supply is maintained. Thus, the impact of operating normal bus service into platoon bus operation by increasing headway has been examined. Comparison were made for the Normal bus operation for 4 minute headway and three bus platoons for 12 minute headway in continuous exclusive bus lane and signal priority has been activated whenever necessary. The efficiency is evaluated in terms of decrease or increase in Bus and other vehicle measures of performances.

The numbers of BSP activation may be reduced when bus operation in platoon was considered. This will help to minimize negative impacts to the general vehicles, there by increasing system efficiency. From Table 4, it was found that BSP with bus platoon operation had increases delay or decrease in speed to the vehicles in cross street. But, the amounts of impact to non-priority vehicles i.e. cross street vehicles are less for option II (14.31\% increase in delay and $2.30 \%$ decrease in speed) compared to option I (26.03\% increase in delay and $7.31 \%$ decrease in speed). The system supply i.e. number of buses served remained same for option II with still increase in speed and

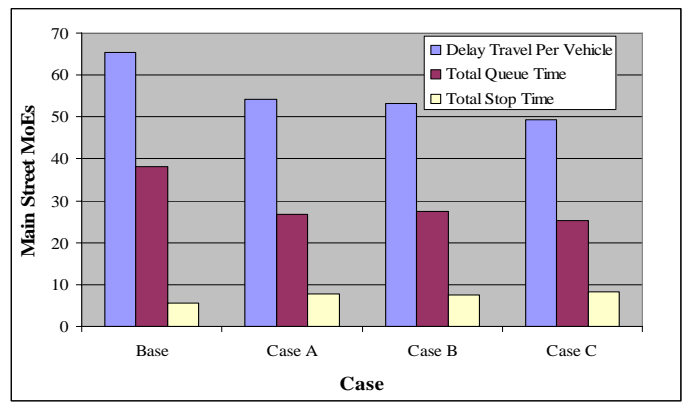

Figure 9 Effect of BSP \& bus platoon on main road

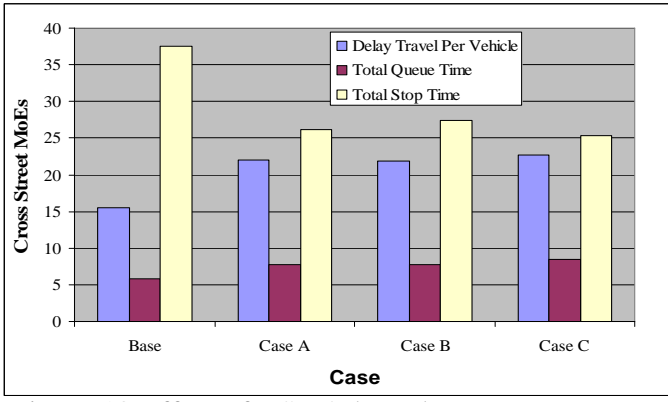

Figure 10 Effect of BSP \& bus platoon on cross road decrease in delay for both bus and vehicles in main street. It may be due to increased numbers of BSP call in the case of normal bus operation than bus platoon operation with larger headway.

Table 5 shows comparison of travel time benefit for the two cases. Total decrease/increase in travel time for main and cross road has been calculated considering bus occupancy of 25 passengers and other vehicle occupancy of 1.5. The total difference between decrease in travel time and increase in travel time named as travel time shows that case 2 where 3 buses are in platoon are efficient in reducing travel time. 
Table 4 Result of Analysis for Case I

\begin{tabular}{|c|c|c|c|c|c|c|c|c|}
\hline \multirow[b]{2}{*}{ Bus Platoon \& BSP } & \multirow{2}{*}{$\begin{array}{l}\text { Headway } \\
\text { (min) }\end{array}$} & \multicolumn{2}{|c|}{ Bus } & \multicolumn{2}{|c|}{ Main Street } & \multicolumn{2}{|c|}{ Cross Street } & \multirow{2}{*}{$\begin{array}{c}\text { Nos. of } \\
\text { Buses } \\
\text { Serviced }\end{array}$} \\
\hline & & $\begin{array}{l}\text { \% Increase in } \\
\text { Delay }\end{array}$ & $\begin{array}{c}\text { \% Increase } \\
\text { in Speed }\end{array}$ & $\begin{array}{c}\text { \% Increase in } \\
\text { Delay }\end{array}$ & $\begin{array}{l}\text { \% Increase } \\
\text { in Speed }\end{array}$ & $\begin{array}{l}\text { \% Increase in } \\
\text { Delay }\end{array}$ & $\begin{array}{c}\text { \% Increase in } \\
\text { Speed }\end{array}$ & \\
\hline Option I : Single & 4 & -19.73 & 11.00 & -15.29 & 57.77 & 26.03 & -7.31 & 13.7 \\
\hline Option II: 3 buses & 12 & -24.28 & 7.99 & -10.59 & 24.84 & 14.31 & -2.30 & 15.1 \\
\hline
\end{tabular}

(5)Case II (Increased Capacity case)

In case of high passenger demand corridor, Buses operating in platoon can provide additional supply at same headway. Assumption is that total passengers will be distributed among the total numbers of buses in platoon. In case of normal bus operation, it takes large time to serve high demand in single bus resulting exceptionally large dwell time. Whereas, in multiple bus operation in platoon, total passenger will be shared among buses in the platoon and the total dwell time will be reduced. The result of analysis for this case in Table 6 shows that $23 \%$ and $24 \%$ delay reduction has been observed for the case of normal bus operation and 3 buses in platoon. Similarly, $11 \%$ and $8 \%$ increase in average speed were observed for normal bus operation and 3 buses in platoon, respectively, while comparing with base case. But total numbers of buses which got benefit was also increased. Thus, total capacity of the system has been increased.

\section{Implementation Issues and Solutions}

(1) Control of bus platoon

The greatest concerned for the bus operation in platoon is how to maintain bus platoon and smooth movement especially if bus has to moving with very short separation. Through the use of Advanced ITS technologies, including communication and information system, Advance vehicle location system might be useful for the control of movements of buses on the bus lane with appropriate spacing. Tsao and Botha (2002) ${ }^{16)}$ stated that Bus convoying though use of ITS resembling that of a light rail system where rail cars are replaced by buses and physical linkage are replaced by electronic linkage can be promising to minimize disturbance to surrounding traffic with capacity as of light rail but flexibility that of buses. The disruption of bus platoon is not only inefficient to bus users, but also produce high disturbance to other vehicles. Two major points of bus platoon disruption and increased spacing are signalized intersection and bus dispatched from bus stop. The platoon disruption at signalized intersection could be able to minimize through priority signal timing considering bus platoon as considered in the case study explained before. For the whole study period, only 2 cases out of 48 are disrupted were found to be interfered even after considering signal priority. Similarly, platoon disruption while departing from bus stop can be prevented by developing proper communication among bus drivers. The drivers are to be instructed to stay at bus stop till all buses are ready to depart. The simple technology of giving some kind of sign to mobile communication could be used.

\section{(2) Control of passenger behavior}

Important issue related to passenger behavior is the selection of bus within platoon by passenger. There is possibility that the passenger use bus near to the crossing resulting passenger crowding at some bus and some bus do not get any passenger. The knowledge to passenger about the stopping position of bus affects the position where they stands while waiting. Usually passenger will stand waiting at or near the shelter. However, when bus platoon has more than one bus, it may lead to more passenger concentration on one bus. Sometime it may disturb alighting passenger causing increased alighting time. Thus, the information about the numbers of bus, bus route and bus occupancy of each bus in bus platoon can be useful to divert passenger among buses. Implementation of automatic passenger counter can estimate the number of bus passengers on board and dissemination of this information in next bus stop can be useful for passenger to make pre-decision on bus they are going to board. It will accelerate passenger boarding process; reduce passenger concentration on single bus and crowding at bus stop. Real-time passenger information system, bus stop announcement of on coming bus information such as its route, occupancy can provide uniformity in passenger bus choice within bus platoon. Also, the bus stop management to distribute passenger among the buses can be an influential solution. The proper placement of sign and dissemination of information where each bus is going to stop and the place where passenger should be waiting plays an important role in bus stop management.

\section{Conclusion}

Thus, this paper has proposed and tests a strategy of systematic operation of buses in platoon along with other priority policies such as bus signal priority and exclusive bus lane. Three cases namely Case A (normal bus operation with BSP), Case 
B (the bus operation in platoon of three buses in Set back bus lane with BSP) and Case C (bus operation in platoon in continuous exclusive bus lane with BSP) have been considered and compared. Since extra lane has been considered for continuous bus lane, bus has got higher benefit of delay reduction and increased speed. However, it was also observed that the bus platoon operation on set back length with BSP also possible by assigning traffic lane as set back lane with sufficient set back to maintain intersection capacity. Thus, measures of effectiveness for other vehicles obtained for Case A and Case B are similar i.e $22.06 \mathrm{sec} / \mathrm{veh}$ and $21.92 \mathrm{veh} / \mathrm{sec}$ total queue time of vehicles on cross street for case A \& B respectively. Also, Bus operation in platoon with other priority policies can be employed to increase passenger carrying capacity of the bus route as well as increase efficiency of the system. While making comparison between normal bus operation for 4 minute headway and three bus platoons for 12 minute headway in exclusive bus lane with signal priority the impact to other vehicle has been lessen i.e. $14.31 \%$ increase in delay while bus operating in platoon in comparison to $26.03 \%$ increase in delay for normal operation. Additionally, it can increase capacity of the system 39.6 bus/hr compared to $13.7 \mathrm{buses} / \mathrm{hr}$ without or small impact to other vehicles.

At last, the greatest concerned for the bus operation in platoon is how to maintain bus platoon and smooth movement. Two major points of bus platoon disruption and increased spacing are signalized intersection and bus dispatched from bus stop. The platoon disruption at signalized intersection could be able to minimize through priority signal timing while platoon disruption while departing from bus stop can be prevented by developing proper communication among bus drivers. Realtime passenger information display or bus stop announcement of on coming bus information such as number of buses in platoon, bus route, occupancy of each bus and the position at which it stop at bus stop will be useful to divert passenger among buses. It will accelerate passenger boarding process; reduce passenger concentration on single bus and crowding at bus stop.

\section{Reference}

1) Shrestha, P.K., Nakamura, F., and Okamura, T.: Evaluation of the Effects of Combining Different Signal Priority Rules and Bus Operation at the Signalized Intersection, Infrastructure Planning Review, 2008

2) Levinson, H. S., Zimmerman, S., Clinger, J., Gast, J., Rutherford, S., and Bruhn, E.: TCRP Report 90 Bus Rapid Transit Volume 2: Implementation Guidelines, Transportation Research Board, 2003

3) Liu, Y., Yu, L., and Chen, X. : Benefit Analysis on Bus Rapid Transit Exclusive Lanes, ASCE Journal of Transportation, pp. 2518-2523, 2007

4) Lin, G., Liang, P., Schonfeld, P., and Larson, R.: Adaptive Control of Transit Operations http:// www. itsdocs.fhwa.dot.gov/JPODOCS/ REPTS_TE/2450.pdf (Access date: July 24, 2008)

5) Jacques, K., and Levinson, H.S. : Operational Analysis of Bus Lanes on Arterials: Application and Refinement, TCRP- RRD-38, National Research Council, Washington, DC, http://gulliver.trb. org/ publications/tcrp/tcrp_rrd_38.pdf (Access date: July 24, 2008)

6) Jaiswal, S., Bunker, J. and Ferreira, L.: Operating Characteristics and Performance of a Busway Transit Station, http://eprints.qut.edu.au/ archive/ 00009844/01/FP_Jaiswal_48.pdf (Access Date: July 24, 2008)

7) Chavala,T., Gillen, D., Klieman, L., and Marshall, A.: Bus Operations in Santa Clara County, Potential Uses of AVL, and Framework for Evaluating Control Strategie, http://www.path.berkeley.edu/ PATH/Publications/PDF/ PRR/99/ PRR-99-25.pdf (Access: July 24, 2008)

8) Meirelles, A.: A Review of Bus Priority Systems in Brazil: from Bus Lanes to Busway Transit, Smart Urban Transport Conference, 17-20 October, Brisbane Australia, 2000

9) Jepson, D and Ferreira, L. Assessing Travel Time Impacts of Measures to Enhance Bus Operations. Part II: Assessment Criteria and Main Findings. Road and Transport Research Journal, 9 (1), page 3-18, 2000

10) CORSIM Documentation, FHWA, US Department of Transportation, 2007

11) Holm, P., Tomich, D., Sloboden, J., and Lowrance, C.: Traffic Analysis Toolbox Vol. IV: Guidelines for Applying CORSIM, Microsimulation Modeling Software. FHWA-HOP-07-079, Available at: http://ops.fhwa.dot.gov/ trafficanalysistools/ tat_vol4/ vol4_guide lines.pdf. [Accessed June 15, 2008]

12) HCM: Highway Capacity Manual, Special Reoprt 209, Transportation Research Board (TRB), 2000.

13) Kim, W. and Rilett, L. R.: Improved Transit Signal Priority System for Networks with Nearside Bus Stops, Journal of Transportation Research Board, Issue No. 1925, pp 205-214, 2005

14) AASHTO: AASHTO Green Book: A Policy on Geometric Design of Highways and Streets, 5th Edition, 2000

15) Gan, A., Yue, H., Ubaka, I., and Zhao, F.: Development of Operational Performance and Decision Models for Arterial Bus Lanes, 82nd Annual Meeting of the Transportation Research Board, Washington, D.C., 2000

16) Tsao, J. and Botha, J.L. : Definition and Evaluation of Bus and Truck Automation Operations Concepts, California PATH Research Report, UCB-ITS-PRR-2002-8, http://www.path.berkeley.edu/PATH/Publications/ PDF/ PRR/2002/PRR-2002-08.pdf (Access date: 3rd February, 2009)

Study on Operation and Performance of Bus Priority Policies Considering Intended Platooning of Bus Arrivals* By Pradeep Kumar SHRESTHA** Fumihiko NAKAMURA*** Toshiyuki OKAMURA****

This study develops and tests a strategy to operate bus on platoon. The bus operation in platoon with bus priority lane increase passenger carrying capacity and efficiency. Three cases normal bus with BSP, bus platoon in set back bus lane with BSP and bus platoon in continuous bus lane with BSP have been compared using simulation method. The BSP to bus platoon has resulted less impact to other vehicles as numbers of priority activated are reduced compared to single bus operation. Finally, it has discussed about implementation issues to prevent platoon disruption and speed up passenger boarding at bus stop. 